\title{
Short communication: Effect of washing method, grinding size, and the determination of an indigestible fraction on in situ degradation of starch in mature corn grain
}

\author{
T. Fernandes, ${ }^{*} \dagger$ C. L. S. Ávila, ${ }^{*}$ M. N. Pereira, ${ }^{*}$ and L. F. Ferraretto ${ }^{1}$ \\ *Department of Animal Sciences, University of Lavras, Lavras, MG 37200-000, Brazil \\ †Department of Animal Sciences, University of Florida, Gainesville 32611
}

\begin{abstract}
The objectives of this study were to determine (1) the effect of grinding size $(1,2,4$, and $6 \mathrm{~mm})$ to determine effective ruminal disappearance (ERD); (2) the most adequate method to estimate the rapidly degradable fraction (A); (3) a time point to measure the indigestible fraction $(\mathrm{C})$; and (4) the viability of using fewer time points to estimate starch fractional disappearance rate $\left(k_{d}\right)$ of mature corn grain. Fraction A was determined by rinsing in a bucket or washing machine, rumen immersion followed by bucket or washing machine, and water immersion for $30 \mathrm{~min}$ followed by bucket or washing machine. Ruminal in situ incubations were performed at 48, 72, 96, and $120 \mathrm{~h}$ to determine fraction $\mathrm{C}$, and at 0 (washing machine), 3,6 , $12,18,24$, and $48 \mathrm{~h}$ to determine the kinetics of starch disappearance. Models were used with either 2 or 3 pools and $k_{d}$ was determined by the linear slope of the log-transformed bag residues as a proportion of incubated samples over time. The ERD was calculated as A $+\mathrm{B}\left[\mathrm{k}_{\mathrm{d}} /\left(\mathrm{k}_{\mathrm{d}}+\mathrm{kp}\right)\right]$, where $\mathrm{kp}$ is the ruminal fractional passage rate $=16.0 \% \mathrm{~h}^{-1}$. Data were analyzed using PROC MIXED of SAS (SAS Institute Inc., Cary, NC) with the fixed effects of run (for fraction A analysis only) method (either washing or model), grinding size, and method by grinding size interaction, with cow as a random effect. Correlation between estimates calculated using all time points or combinations of 2 and 3 time points were determined using PROC CORR. Fraction A was reduced as grinding size increased, but was not altered by washing method. Samples ground at $6 \mathrm{~mm}$ had greater fraction $\mathrm{C}$ than other grinding sizes at 48,72 , or $96 \mathrm{~h}$, but not at $120 \mathrm{~h}$. Model affected the slowly degradable fraction (B) values solely, but the difference was minor (0.5 percentage units). Greater fractions $\mathrm{B}$ and $\mathrm{C}$ but reduced $\mathrm{k}_{\mathrm{d}}$ and $\mathrm{ERD}$
\end{abstract}

Received April 3, 2018.

Accepted June 22, 2018.

${ }^{1}$ Corresponding author: lferraretto@ufl.edu were observed as grinding size increased. Based on correlation analysis the 2-pool model, incubation times of 0,3 , and $48 \mathrm{~h}$ were suitable to evaluate ruminal starch degradation kinetics in mature corn. Ruminal in situ incubation at $120 \mathrm{~h}$ highlighted the lack of a fraction $\mathrm{C}$ of starch $(0.13 \%$ of starch). Washing method did not affect determination of fraction A of starch. Ruminal in situ incubations of 0,3 , and $48 \mathrm{~h}$ for starch degradation kinetics using a 2-pool model were adequate for mature ground corn, but $120 \mathrm{~h}$ of incubation is suggested to confirm the existence or absence of a fraction C. Grinding size affected starch degradation kinetics and fraction A determination.

Key words: soluble fraction, effective ruminal degradation, fractional degradation rate, starch

\section{Short Communication}

Starch is a major energy source for both ruminant animals and ruminal microorganisms (Moharrery et al., 2014). However, ruminal in vivo starch digestibility varies from 25 to $95 \%$ of intake, which in turn may alter lactation performance and feed efficiency by dairy cows (Firkins et al., 2001; Ferraretto et al., 2013). Nevertheless, it is difficult to account for this variation in nutritional models, as a standard method established to evaluate the ruminal disappearance of starch has not been defined (Peyrat et al., 2014). Considering that predicting total-tract starch digestibility from fecal starch concentration is reliable (Fredin et al., 2014), an accurate estimation of ruminal starch digestibility would provide useful information for ration formulation, as it alters efficiency of energy usage, ruminal microbial synthesis, and the occurrence of ruminal acidosis (Krause et al., 2002; Firkins et al., 2006). Furthermore, more accurate predictions to rank feedstuffs would benefit various industry sectors.

The ruminal in situ digestibility method is one of the standard procedures used for determination of ruminal starch digestibility through the measurement of nutrient disappearance from bags containing feed samples and 
incubated in the rumen across various time points (Seifried et al., 2016). With the use of several time points, we could determine the soluble or rapidly degradable fraction (fraction $\mathrm{A}$ ), the slowly degradable fraction (fraction $\mathrm{B}$ ), and the indigestible fraction (fraction $\mathrm{C}$ ); however, this procedure is not standardized with amount and length of time points varying substantially (Dias Junior et al., 2016; Seifried et al., 2016; Dieho et al., 2017). The ruminal in situ technique may also be affected by other factors. For example, the sample particle size may interfere with the estimation of ruminal degradation due to the potential loss of small particles through the pores of incubation bags (Philippeau and Michalet-Doreau 1997), and grinding size varies across laboratories. Furthermore, different methodologies applied during bag washing can affect the estimation of fraction A. Moreover, the interaction between grinding size and washing method or time points to determine fractions $\mathrm{A}$ and $\mathrm{C}$, respectively, is undefined and warrants further investigation.

The lack of a standardized method makes the comparison among feeds analyzed by different research laboratories unfeasible and hinders the ranking of feedstuffs and the establishment of more precise prediction models. Therefore, our experimental objectives were (1) to determine the effect of grinding size on fractions $\mathrm{A}$ and $\mathrm{C}$, starch fractional disappearance rate $\left(\mathbf{k}_{\mathrm{d}}\right)$, and effective ruminal disappearance (ERD) in mature ground corn; (2) to evaluate washing methods to estimate fraction $\mathrm{A}$ of starch; (3) to determine a time point to measure fraction $\mathrm{C}$ of starch; (4) to determine the correlation between starch $\mathrm{k}_{\mathrm{d}}$ estimated with various time points; and (5) to measure starch ERD and $\mathrm{k}_{\mathrm{d}}$ of various starch sources using the methodology defined by objectives 2,3 , and 4 . We hypothesized that grinding size would play a major role in estimating ERD in mature ground corn and that the use of a methodology with few incubation time points to calculate starch ruminal degradation kinetics would yield the same ERD as the prediction performed with all time points.

A batch of $4 \mathrm{~kg}$ of dried mature corn was homogenized and allocated into 4 samples using a quartering technique. Briefly, samples were homogenized in a bag and divided into 4 equal subsamples; 2 subsamples were saved for later treatment, whereas the 2 other subsamples were rehomogenized and redivided. The process was repeated until 4 subsamples of $500 \mathrm{~g}$ were prepared. Each subsample was assigned to a grinding size and ground to pass 1-, 2-, 4-, or 6-mm sieves in a Wiley mill (A. H. Thomas Scientific, Philadelphia, PA). Each sample $(82.4 \pm 14.5 \mathrm{~g}$; mean $\pm \mathrm{SD})$ was dry sieved using a Tyler Ro-Tap Shaker (model RX-29, W.S. Tyler, Mentor, $\mathrm{OH}$ ) using a set of 9 sieves (W.S. Tyler) with nominal square apertures of $6.70,4.75,3.35,2.36$,
$1.70,1.18,0.59,0.20$, and $0.15 \mathrm{~mm}$ and a pan (ASABE, $2007)$ to determine particle size distribution. Geometric mean particle size $(\mu \mathrm{m})$ and surface area $\left(\mathrm{cm}^{2} / \mathrm{g}\right)$ were calculated using a log normal distribution (Baker and Herrman 2002).

Ruminal in situ procedures were conducted at the University of Florida Dairy Research Unit (Gainesville, FL) under a protocol approved by the University of Florida, Institute of Food and Agricultural Sciences, Animal Care Research Committee. Dacron polyester cloth bags $(\mathrm{R} 1020,10 \times 20 \mathrm{~cm}$ and $50 \pm 10$ micro porosity; Ankom Technology, Macedon, NY) containing $5.04 \pm 0.02 \mathrm{~g}$ of DM, yielding a ratio of sample mass per bag area of $16.6 \mathrm{mg} / \mathrm{cm}^{2}$, were used to compare fraction A methods, to determine a time point to measure fraction $\mathrm{C}$, and to estimate $\mathrm{k}_{\mathrm{d}}$ of fraction $\mathrm{B}$ and ERD.

A comparison of 6 methodologies used to determine fraction A of starch was performed. Three independent runs were conducted per method, and samples from each grinding size were used in duplicate within each run. Each run and method contained a blank bag to allow correction for infiltration of DM into sample bags. Methods were (1) to rinse bags until water was clear $(6 \pm 2 \mathrm{wash} / \mathrm{bag})$ in a bucket with water at room temperature (approximately $22^{\circ} \mathrm{C}$ ); (2) to rinse in a washing machine using the rinse and spin cycle set with room temperature water for a 30-min cycle (Roper RTW4516F*, Whirlpool Corp., Benton Harbor, MI); (3) to insert bags in the rumen, remove immediately after moistened, soak in cold water (water + ice) for $15 \mathrm{~min}$, and rinse in a bucket until water was clear; (4) to insert bags in the rumen, remove immediately after moistened, soak in cold water for $15 \mathrm{~min}$, and rinse using a washing machine set as described for treatment $2 ;(5)$ to submerge bags in water (approximated $22^{\circ} \mathrm{C}$; $1,000 \mathrm{~mL} \mathrm{bag}$ ) for $30 \mathrm{~min}$, and rinse it in a bucket until water was clear; and (6) to submerge bags in water (approximately $22^{\circ} \mathrm{C} ; 1,000 \mathrm{~mL} \mathrm{bag}$ ) for $30 \mathrm{~min}$, and rinse it using a washing machine set as described for treatment. All 6 methods were performed simultaneously for each run and all bags were dried together in a forced-air oven set at $60^{\circ} \mathrm{C}$ for $48 \mathrm{~h}$. Residues from duplicates within each grinding size treatment for each fraction A method within run were composited and ground to pass the 1-mm sieve in a cyclone mill (UDY Corporation, Fort Collins CO) and analyzed for starch by an enzymatic method (Hall, 2015) with thermostable $\alpha$-amylase (Ankom Tchnology, Macedon, NY) and amyloglucosidase (Megazyme E-AMGDF, Bray, Co. Wicklow, Ireland) enzymes.

To define the incubation time for fraction $\mathrm{C}$ determination, measurements of ruminal in situ starch degradation were performed for each grinding size using 3 ruminally cannulated, midlactation, multiparous 
Holstein cows fed a TMR containing (DM basis) corn silage $(38.2 \%)$, alfalfa hay $(4.0 \%)$, dry ground shelled corn $(27.3 \%)$, soybean meal (14.5\%), citrus pulp (9.1\%), and minerals and supplements $(6.8 \%)$. The in situ bags for each grinding size treatment for each time point (48, 72,96 , and $120 \mathrm{~h}$ ) were incubated as described by Dias Junior et al. (2016). After removal, samples were soaked in ice water for $15 \mathrm{~min}$, rinsed as described for rinsing in a washing machine, and dried, ground, and analyzed for starch as described previously. Subsequently, the same cows and procedures were used to determine the kinetics of starch disappearance, but using different incubation time points $(3,6,12,18,24$, and $48 \mathrm{~h})$. Two models were used to determine fraction $\mathrm{B}$. The first model consisted of 3 fractions (A, B, and $\mathrm{C}$ ), with fraction $\mathrm{B}$ estimated by the equation $\mathrm{B}=100-\mathrm{A}-\mathrm{C}$. The second model consisted of 2 fractions ( $\mathrm{A}$ and $\mathrm{B}$ ), with fraction $\mathrm{B}$ estimated by the equation $\mathrm{B}=100-\mathrm{A}$. The second model assumed indigestible fraction (fraction $\mathrm{C}$ ) in starch (based on our fraction $\mathrm{C}$ results). Fractional disappearance rate $\left(\mathrm{k}_{\mathrm{d}}\right)$ was determined by the linear slope over time of the natural logarithm of each time point residue as a percentage of the incubated material. This calculation was performed for each time point of each sample in each cow, which resulted in a linear regression of fraction $B$ for each model. The ERD was calculated as $\mathrm{A}+\mathrm{B}\left[\mathrm{k}_{\mathrm{d}} /\left(\mathrm{k}_{\mathrm{d}}+\mathrm{kp}\right)\right]$, where: $\mathrm{A}=$ fraction $\mathrm{A}, \mathrm{B}=$ fraction $\mathrm{B}, \mathrm{k}_{\mathrm{d}}=$ fractional degradation rate of fraction $\mathrm{B}$, and $\mathbf{k p}=$ fractional passage rate. The $\mathrm{kp}$ rate used was $16 \% \mathrm{~h}^{-1}$ similarly to the Feed Grain V2 model (Hoffman et al., 2012). Based on these data, the most suitable time points $(0,3,48$, and $120 \mathrm{~h})$ of ruminal in situ incubation were defined and performed to measure fractions $\mathrm{A}, \mathrm{B}$, and $\mathrm{C}$, as well as $\mathrm{k}_{\mathrm{d}}$ of fraction $\mathrm{B}$ and ERD from various starch sources on 2-mm ground samples, as described previously.
Fraction A data were analyzed using PROC MIXED of SAS (version 9.4; SAS Institute Inc., Cary, NC), the model included the fixed effects of run, washing procedure, grinding size $(1,2,4$, and $6 \mathrm{~mm})$, and their interaction. Fraction $\mathrm{C}$ of starch degradation data were also analyzed using PROC MIXED (SAS Institute Inc.). The model included the fixed effects of grinding size $(1,2,4$, and $6 \mathrm{~mm})$, incubation time $(48,72,96$, and 120 for fraction $\mathrm{C}$ ), and their interaction, with cow as a random effect. For $\mathrm{k}_{\mathrm{d}}$ of fraction $\mathrm{B}$ and ERD estimates, data were analyzed using PROC MIXED of SAS, with a model inclusive of the fixed effects of grinding size (1, 2 , 4 , and $6 \mathrm{~mm}$ ), model (2- or 3-pool), and the interaction of grinding size and model, with cow as a random effect. Means were determined using the least squares means statement and treatment means were compared using the Bonferroni $t$-test option after a significant overall treatment $F$-test. Statistical significance were declared at $P \leq 0.05$. To determine if accurate $\mathrm{k}_{\mathrm{d}}$ estimates could be obtained with fewer ruminal in situ incubation time points, a subsequent data analysis was performed to analyze the correlation and relationships between estimates calculated using all time points, 0 (fraction A), 3, 6, 12, 18, 24, and $48 \mathrm{~h}$, and estimates calculated using combinations of 3 or 2 time points were determined using the CORR and REG procedures of SAS, respectively.

Nutrient composition and particle size distribution of ground corn grain are in Table 1. Starch composition of corn was $65.9 \%$, with a standard deviation of $0.55 \%$ among different grinding size samples. This variation is not biologically expressive, and it is likely related to the method used for starch analyses; according to Hall (2015), the standard deviation within samples of dry ground corn was $0.34 \%$. The range in geometric mean particle size was 390 to $1,181 \mu \mathrm{m}$ for

Table 1. Dry matter and starch concentrations, particle size distribution, geometric mean particle size (GMPS), and surface area of dry corn ground at varying grinding sizes

\begin{tabular}{lcccc}
\hline & \multicolumn{4}{c}{ Grinding size } \\
\cline { 2 - 5 } Item & $1 \mathrm{~mm}$ & $2 \mathrm{~mm}$ & $4 \mathrm{~mm}$ & $6 \mathrm{~mm}$ \\
\hline DM, \% as fed & 89.5 & 89.5 & 89.5 & 89.3 \\
Starch, \% of DM & 65.8 & 66.5 & 65.2 & 66.1 \\
Free glucose, \% of DM & 0.63 & 0.71 & 0.63 & 0.68 \\
Sieves, \% of particles retained, DM basis & & & & \\
$3,350 \mu \mathrm{m}$ & 0.0 & 0.0 & 0.1 & 3.9 \\
$2,360 \mu \mathrm{m}$ & 0.3 & 0.1 & 1.6 & 24.5 \\
$1,700 \mu \mathrm{m}$ & 0.3 & 0.1 & 13.9 & 35.7 \\
$1,180 \mu \mathrm{m}$ & 0.7 & 17.9 & 55.7 & 21.6 \\
$600 \mu \mathrm{m}$ & 80.0 & 73.5 & 22.7 & 11.0 \\
$300 \mu \mathrm{m}$ & 17.0 & 6.2 & 4.3 & 2.3 \\
$150 \mu \mathrm{m}$ & 1.6 & 1.9 & 1.5 & 0.9 \\
Bottom pan & 0.1 & 0.1 & 0.1 & 0.1 \\
GMPS, $\mu \mathrm{m}$ & 390 & 468 & 746 & 1,181 \\
Surface area, $\mathrm{cm}^{2} / \mathrm{g}$ & 41.0 & 39.2 & 34.2 & 29.0 \\
\hline
\end{tabular}




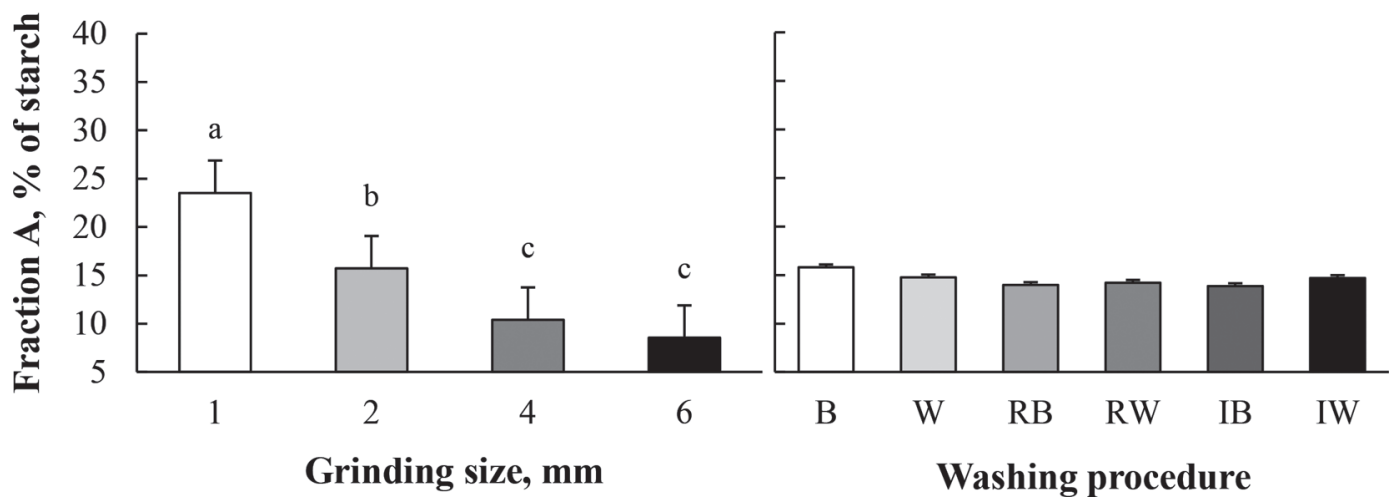

Figure 1. Fraction A of starch (\% of starch) of dry corn ground at different grinding sizes (1 mm, white; $2 \mathrm{~mm}$, light gray; $4 \mathrm{~mm}$, dark gray; and $6 \mathrm{~mm}$, black) and determined by different washing procedures [rinsing in a bucket (B), white; rinsing in a washing machine (W), light gray; inserting in the rumen and rinsing in a bucket (RB), medium-light gray; inserting in the rumen and rinsing in the washing machine (RW), medium-dark gray; immersing in warm water during 30 min and rinsing in a bucket (IB), dark gray; and immersing in warm water during 30 min and rinsing in the washing machine (IW), black]. Effects of grinding size $(P=0.001)$, washing method $(P=0.82)$, and interaction between grinding size and washing method $(P=0.94), \mathrm{SEM}=2.140$. Means with different letters $(\mathrm{a}-\mathrm{c})$ differ at $P \leq 0.05$ by pairwise $t$-test.

samples ground using sieves of 1 to $6 \mathrm{~mm}$. Fraction A of starch was reduced $(P<0.01)$ with increased grinding size (Figure 1A). Particle size interferes with nutrient degradation, as increased grinding size reduces surface area and thereby may impair the attachment of ruminal microorganisms and the action of their enzymes (McAllister et al., 1993). Furthermore, with reduced surface area the amount of nutrient in contact with water is decreased, a plausible explanation for the reduction of 14.98 percentage units in the soluble fraction of starch (Figure 1A). Fraction A of starch was unaffected $(P=0.82)$ by washing procedure. An interaction between grinding size and incubation time was observed $(P=0.01$; Figure 2$)$ for fraction $\mathrm{C}$ of starch. At $48 \mathrm{~h}$ of incubation, samples ground at 6 $\mathrm{mm}$ had the greatest, at $4 \mathrm{~mm}$ intermediate, and 1 and $2 \mathrm{~mm}$ the lowest values of fraction $\mathrm{C}$; after $72 \mathrm{~h}$ of incubation, fraction $\mathrm{C}$ was greater for $6 \mathrm{~mm}$ compared with other treatments, and at 96 or $120 \mathrm{~h}$ grinding size did not affect fraction $\mathrm{C}$.

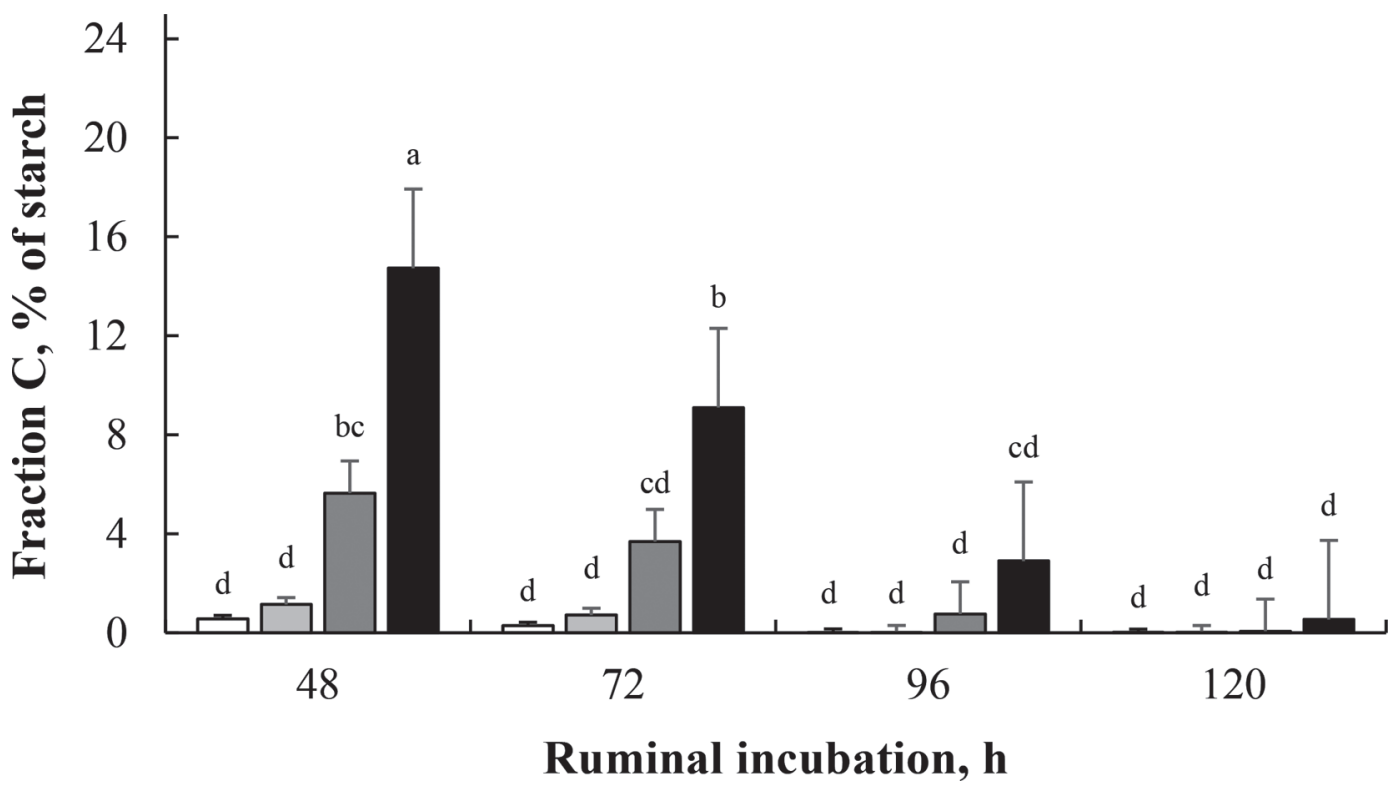

Figure 2. Fraction $\mathrm{C}$ of starch (\% of starch) of dry corn ground at different grinding sizes ( $\mathrm{mm}$, white; $2 \mathrm{~mm}$, light gray; $4 \mathrm{~mm}$, dark gray; and $6 \mathrm{~mm}$, black) and incubated for different time points of ruminal in situ disappearance $(48,72,96$, and $120 \mathrm{~h})$. Effects of grinding size $(P=$ $0.001)$, incubation time $(P=0.001)$, and interaction between grinding size and incubation time $(P=0.001)$, SEM $=1.960$. Means with different letters $(\mathrm{a}-\mathrm{d})$ differ at $P \leq 0.05$ by pairwise $t$-test. 
Ruminal disappearance kinetics of starch are in Table 2. Although the effects of grinding size $(P<0.01)$ were observed for all starch parameters, model $(P<0.01)$ and interaction between grinding size and model were observed solely on fraction B. However, fraction B differences between models were not biologically meaningful (less than 0.5 percentage units). These data suggest that a model of 2 pools is adequate to determine starch digestion kinetics in mature ground corn. Previously, Herrera-Saldana et al. (1990) used a 2-pool model to estimate the $\mathrm{k}_{\mathrm{d}}$ of DM, starch, and CP of cereal grains. The correlation coefficients of $k_{d}$ estimated with all time points of ruminal in situ incubation $(0,3,6,12$, 18,24 , and $48 \mathrm{~h}$ ) and the combination of 2 or 3 time points are in Supplemental Table S1 (https://doi.org/ 10.3168/jds.2018-14870). All $\mathrm{k}_{\mathrm{d}}$ calculated with the 48-h incubation time point had linear correlation coefficients greater than 0.99 except for the $\mathrm{k}_{\mathrm{d}}$ estimated with incubations for 24 and $48(\mathrm{r}=0.938)$, suggesting that the 48-h incubation is required for accurate determination of the $\mathrm{k}_{\mathrm{d}}$ of fraction $\mathrm{B}$. The greatest linear correlation coefficient $(\mathrm{r}=0.998)$ was obtained with combination of 0,3 , and $48 \mathrm{~h}$ of incubation. Other combinations that could be used are 0,6 , and $48 \mathrm{~h}$, as they present similar characteristics. According to Vanzant et al. (1998), the use of simple modeling strategies may offer some benefits relative to facilitating the application without compromising the accuracy or precision of estimates. However, these results were obtained with mature ground corn and further research is warranted with other cereal grains and varied endosperm types.

Based on previous results, a 2-pool model and incubation times of 0,3 , and $48 \mathrm{~h}$ were used to determine the ruminal kinetics parameters of starchy feedstuffs; these results are in Supplemental Table S2 (https://doi.org/ 10.3168/jds.2018-14870). Ruminal in situ incubation at $120 \mathrm{~h}$ highlighted that fraction $\mathrm{C}$ was marginal for most feedstuffs, as the residue amount is not biologically meaningful. However, further research evaluating these feedstuffs from various sources and under varied conditions are warranted. The variation $(\mathrm{SD}=18.8)$ in the ERD estimate ranged from 25.5 to $96.9 \%$, with an average of $65.7 \%$. This variation is similar to the variation $(\mathrm{SD}=18.5)$ of values obtained in a meta-analysis conducted with in vivo data with a range of 22.4 to $94.2 \%$ and an average of $68.1 \%$ of ruminal starch digestibility (Moharrery et al., 2014). These data suggest that the in situ procedure may represent the variation of ruminal starch degradation of feedstuffs, similar to the in vivo evaluation. It should be emphasized, however, that the calculated range in ruminal digestibility of starch in feedstuffs, although biologically coherent, assumes a constant $\mathrm{kp}$ for all starch sources. The concentration of starch in the diet, DMI, and source of starch are

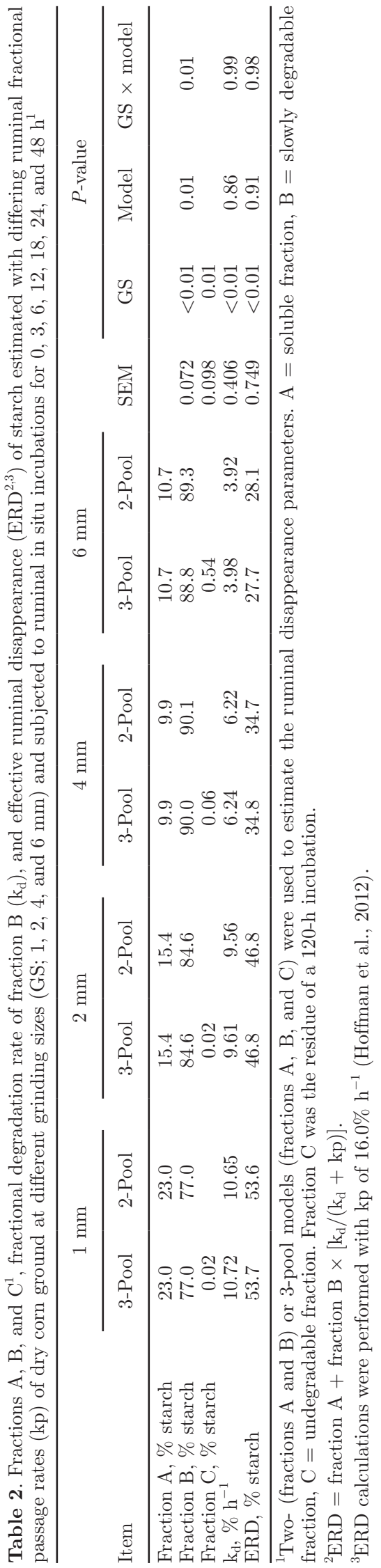


known factors affecting starch $\mathrm{kp}$ and the role of the intestines on total-tract starch digestibility (Oba and Allen, 2003). The use of a constant starch $\mathrm{kp}$ for all feedstuffs is a major imprecision in nutritional models attempting to predict ruminal starch degradation, and its quantification under different feeding scenarios is a plausible field for future research aiming at improving the accuracy of starch ERD predictions for ration formulation.

In summary, no effects of washing methodology were observed for fraction A of starch in the present study, these data suggest that all evaluated methods are adequate to determine fraction $\mathrm{A}$ of starch in mature corn. Our results underscore that fraction $\mathrm{C}$ of starch is minimal $(0.13 \%$ of starch, on average, among all grinding sizes) in mature ground corn, and a model with 2 pools (fractions A and B) represents the starch degradation kinetics. However, differences in particle size and among different feedstuffs suggest that ruminal in situ incubation at $120 \mathrm{~h}$ is necessary to determine fraction $\mathrm{C}$ or the lack of it. As expected, grinding size affected all fractions, disappearance rate, and effective ruminal disappearance; the use of $6 \mathrm{~mm}$ is recommended. A strong correlation was observed between 0,3 , and $48 \mathrm{~h}$ of incubation and the whole set of time points to determine starch fractional disappearance rate, suggesting that under the conditions of the present study (i.e., mature ground corn) the use of fewer time points to evaluate digestibility and rank feedstuffs in the field is feasible. Future research is warranted for various cereal grains and endosperm types.

\section{ACKNOWLEDGMENTS}

Appreciation is extended to Todd Pritchard (University of Florida Dairy Research Unit, Gainesville, FL) for assisting with the use of cannulated cows. The authors are also grateful to the Brazilian Federal Agency for Post-Graduate Education (CAPES; Brasilia, DF, Brazil) and National Research Council (CNPq; Brasilia, DF, Brazil) for the grants to the authors.

\section{REFERENCES}

ASABE. 2007. Method of determining and expressing fineness of feed materials by sieving. ANSI/ASAE S319.4:646-649. Am. Soc. Ag. Biol. Eng., St. Joseph, MI.
Baker, S., and T. Herrman. 2002. Evaluating particle size. MF-2051. Kansas State Univ., Manhattan.

Dias Junior, G. S., L. F. Ferraretto, G. G. S. Salvati, L. C. de Resende, P. C. Hoffman, M. N. Pereira, and R. D. Shaver. 2016. Relationship between processing score and kernel-fraction particle size in whole-plant corn silage. J. Dairy Sci. 99:2719-2729.

Dieho, K., B. Van den Bogert, G. Henderson, A. Bannink, J. RamiroGarcia, H. Smidt, and J. Dijkstra. 2017. Changes in rumen microbiota composition and in situ degradation kinetics during the dry period and early lactation as affected by rate of increase of concentrate allowance. J. Dairy Sci. 100:2695-2710.

Ferraretto, L. F., P. M. Crump, and R. D. Shaver. 2013. Effect of cereal grain type and corn grain harvesting and processing methods on intake, digestion and milk production by dairy cows through a meta-analysis. J. Dairy Sci. 96:533-550.

Firkins, J. L., M. L. Eastridge, N. R. St-Pierre, and S. M. Noftsger. 2001. Effects of grain variability and processing on starch utilization by lactating cattle. J. Anim. Sci. 79:E218-E238.

Firkins, J. L., A. N. Hristov, M. B. Hall, G. A. Varga, and N. R. StPierre. 2006. Integration of ruminal metabolism in dairy cattle. J. Dairy Sci. 89(E. Suppl.):E31-E51.

Fredin, S. M., L. F. Ferraretto, M. S. Akins, P. C. Hoffman, and R D. Shaver. 2014. Fecal starch as an indicator of total-tract starch digestibility by lactating dairy cows. J. Dairy Sci. 97:1862-1871.

Hall, M. B. 2015. Determination of dietary starch in animal feeds and pet food by an enzymatic-colorimetric method: Collaborative study. J. AOAC Int. 98:397-409.

Herrera-Saldana, R. E., J. T. Huber, and M. H. Poore. 1990. Dry matter, crude protein, and starch degradability of five cereal grains. J. Dairy Sci. 73:2386-2393.

Hoffman, P. C., R. D. Shaver, and D. R. Mertens. 2012. Feed Grain V2.0 Background and development guide. Accessed Dec. 5, 2017. https://shaverlab.dysci.wisc.edu/spreadsheets.

Krause, K. M., D. K. Combs, and K. A. Beauchemin. 2002. Effects of forage particle size and grain fermentability in midlactation cows. II. Ruminal pH and chewing activity. J. Dairy Sci. 85:1947-1957.

McAllister, T. A., R. C. Phillippe, L. M. Rode, and K.-J. Cheng. 1993. Effect of the protein matrix on the digestion of cereal grains by ruminal microorganisms. J. Anim. Sci. 71:205-212.

Moharrery, A., M. Larsen, and M. R. Weisbjerg. 2014. Starch digestion in the rumen, small intestine, and hind gut of dairy cows- $\mathrm{A}$ meta-analysis. Anim. Feed Sci. Technol. 192:1-14.

Oba, M., and M. S. Allen. 2003. Effects of corn grain conservation method on ruminal digestion kinetics for lactating dairy cows at two dietary starch concentrations. J. Dairy Sci. 86:184-194.

Peyrat, J., P. Nozièrea, A. Le Morvana, A. Férard, P. V. Protin, and R. Baumon. 2014. Effects of ensiling maize and sample conditioning on in situ rumen degradation of dry matter, starch and fibre. Anim. Feed Sci. Technol. 196:12-21.

Philippeau, C., and B. Michalet-Doreau. 1997. Influence of genotype and stage of maturity of maize on rate of ruminal starch degradation. Anim. Feed Sci. Technol. 68:25-35.

Seifried, N., H. Steinga, W. Schipprack, and M. Rodehutscord. 2016. Variation in ruminal in situ degradation of crude protein and starch from maize grains compared to in vitro gas production kinetics and physical and chemical characteristics. Arch. Anim. Nutr. 70:333-349.

Vanzant, E. S., R. C. Cochran, and E. C. Titgemeyer. 1998. Standardization of In situ techniques for ruminant feedstuff evaluation. J. Anim. Sci. 76:2717-2729. 